\title{
Zeit ist Geld - sprachliche Universalien in der deutschen und polnischen Phraseologie und Parömiologie am lexikographischen Material
}

\author{
Mariusz Frąckowiak (Oppeln)
}

\begin{abstract}
The present article entitled "Time is Money - Linguistic Universals in the German and Polish Phraseology, as well as Paremiology on the Example of Lexographical Material" constitutes an analysis of phrasemes and proverbs in the German and Polish language, which contain in their vocabulary the components of time and money. The author of the paper presented the methods of conceptualisation, using the mono- and bilingual dictionaries, of time and money in the hackneyed linguistic phrases of both cultural communities. Undoubtedly, time and money are verbalised in the examined German and Polish phrasemes and proverbs in a similar or identical manner. Thus, these compounds function as internationalisms, as well as phraseological universals.
\end{abstract}

\section{Zielsetzung, Problemstellung, Materialgrundlage und Methode}

Was die Sprache für den Menschen bedeutet, was sie für ihn leistet, wie sie es leistet, erkennt man am besten, wenn man verschiedene Sprachen miteinander vergleicht. Man kann dafür Sprachen wählen, die einander so fremd sind wie Deutsch und Chinesisch: dann ermisst man, was alles ganz anders sein kann und was auch dann noch gemeinsam ist. Genauere Auskünfte erhält man, wenn man nahe verwandte Sprachen miteinander vergleicht.

(Wandruszka 1969, zit. in Szczęk 2010: 14)

Der vorliegende Beitrag setzt sich zum Ziel, die sprachlichen Universalien Zeit und Geld an ausgewählten Belegen der deutschen und polnischen Phraseologie sowie Parömiologie einer konfrontativen und quantitativen Analyse zu unterziehen und die Ergebnisse dieser Untersuchung zu präsentieren. Das Vorhaben ist dabei, die Inhalte der erwähnten Forschungsdisziplinen zu erforschen, die mittels beider Titellexeme zum Ausdruck gebracht werden. Im Artikel sind die lexikalisch-semantischen Gemeinsamkeiten in der deutschen und polnischen Phraseologie und Parömiologie von Belang. In den empirischen Unterkapiteln 3.1. und 3.2. wird eine Klassifikation der deutschen und polnischen Zeit- und Geld-Phraseologismen und Sprichwörter erstellt. Für diese Phraseologismen und Sprichwörter werden zudem Äquivalenztypen und deutsche Erläuterungen angegeben. Die Ausgangssprache ist Deutsch, das dem Polnischen gegenübergestellt wird. Daher werden als Grundlage dieser Studie ausgewählte 
ein- und zweisprachige Wörterbücher und drei Internetseiten mit elektronischen deutschen und deutsch-polnischen, polnisch-deutschen Wörterbüchern herangezogen. ${ }^{1}$

Anhand der Analyse des sprachlichen Materials sollen zwei Hauptfragen ergründet werden, nämlich wie Zeit und Geld in der deutschen und polnischen Kulturgemeinschaft konzeptualisiert werden und welche Gemeinsamkeiten in der Wahrnehmung dieser kulturellen Universalien beide Sprachen aufweisen. Die Überlegungen werden auf die deutsche und die polnische Sprachkultur beschränkt.

Im Beitrag wird von der These ausgegangen, dass ausgewählte deutsche und polnische Zeitund Geld-Phraseologismen und Sprichwörter als (übereinzelsprachliche) Universalien im engeren Sinne ${ }^{2}$ interpretiert werden können. Mithilfe dieser Einheiten wird die Wirklichkeit der beiden Kulturen auf ähnliche bzw. identische Art und Weise verbalisiert, was sich aus den gleichen sprachlichen Bedürfnissen der beiden Sprachgemeinschaften ergibt. Untersucht werden deswegen nur diejenigen festen Wortverbindungen ${ }^{3}$ und Sprichwörter, die in den beiden analysierten Sprachen sowohl metaphorische Bedeutungen tragen als auch sich mit vollständiger bzw. partieller Äquivalenz charakterisieren. Daraus resultiert die Tatsache, dass viele Zeit- und Geld-Phraseologismen und Sprichwörter zu Interphraseologismen bzw. "Trägern der phraseologischen Universalien" ${ }^{4}$ gerechnet werden können.

Unter Interphraseologismen werden solche Einheiten verstanden, die Gemeinsamkeiten kultureller Tradition aufweisen bzw. gleiche kulturelle Wurzeln haben. Interlinguale Beziehungen in der Phraseologie europäischer Sprachen sind v. a. in der Antike und im Christentum zu bemerken (vgl. Fleischer 1997: 243). Es lassen sich folgende Interphraseologismen erwähnen, deren Vorhandensein sowohl im deutschen als auch im polnischen Kulturkreis nachzuweisen ist: Arbeit schändet nicht-̇̇adna praca nie chańbi: 'es ist nicht unehrenhaft, seinen Lebensunterhalt durch Arbeit zu verdienen, selbst wenn es sich dabei um eine weniger angesehene Art der Betätigung handelt'; Auge um Auge, Zahn um Zahn - oko za oko, zą za ząb: 'bei erlittenem Schaden/Unrecht wird Gleiches mit Gleichem vergolten'; eine Schlange am Busen nähren - wyhodować żmije na własnym łonie (oder na własnej piersi): 'jemandem, in dessen hinterlistigem, heimtückischem Wesen man sich täuscht, vertrauen und Gutes erweisen' und ein Wolf im Schafspelz - wilk w owczej skórze: 'ein Mensch mit üblen Absichten, der sich aber äußerlich sanft und friedlich gibt' (vgl. Szczęk 2010: 181, 188; Duden 2008: 56, 77, 669, 880).

\footnotetext{
${ }^{1}$ Siehe Quellenverzeichnis am Ende des Beitrags.

${ }^{2}$ Im Artikel handelt es sich um die Implikationsbeziehung: Wenn im Deutschen Zeit- und Geld-Phraseologismen vorhanden sind, dann müssen sie ihre polnischen Entsprechungen besitzen (und umgekehrt).

${ }^{3} \mathrm{Im}$ vorliegenden Beitrag bediene ich mich abwechselnd der Begriffe Phraseologismus und feste Wortverbindung, die in der Fachliteratur synonym gebraucht werden.

${ }^{4}$ Universalien bedeutet übereinzelsprachspezifische Elemente, die in mehreren Sprachen gleich oder ähnlich wahrgenommen und beschrieben werden und deswegen einen universellen Charakter haben (vgl. Szczęk 2010: 176).
} 


\section{Begriffsbestimmung: Phraseologismus und Sprichwort in der deutschen und pol-} nischen Fachliteratur

"In der Phraseologie jeder Sprache spiegelt sich das Leben des jeweiligen Volks, das sich der Sprache bedient, wider, seine materielle und geistige Kultur" (Szober 1937: 93). Dabei gelten Phraseologismen als Kulturerbe einer Sprache und werden als Kulturzeichen interpretiert, die Auskunft über Anschauungen, Geschichte, historische Erscheinungen des gesellschaftlichen sowie politischen Lebens, Traditionen, Welt und Werte der jeweiligen Kulturgemeinschaften geben (vgl. Siewert 2012: 287). Nach Bralczyk (2004: 78) "po frazeologii rozpoznajemy przynależność lub celowe działania identyfikacyjne ludzi, gdy chodzi o ich poglądy społeczne, stanowiska polityczne czy przekonania religijne. We frazeologii [...] upatruje się trwałości językowych przekazów myśli, w ustabilizowanych, czasem wręcz spetryfikowanych połączeniach wyrazowych odnajdujemy gotowe do powielania deklaracje i półfabrykaty tekstów" ${ }^{5}$. Związki frazeologiczne sprzyjają utrwalaniu poglądów odnośnie obrazu świata, realiów obyczajowo-społecznych minionych epok, a także ludzkich przekonań ${ }^{6}$ (vgl. Pajdzińska 2006: 61).

Der Ausgangspunkt für die Zusammenstellung des deutschen und polnischen Korpus bilden deutsche und polnische Definitionen des Phraseologismus nach Fleischer (1983, 1997), Burger (2007), Grochowski (1982) und Wotjak (1992) sowie des Sprichworts nach Seiler (1922), Mieder und Röhrich (1977), Krzyżanowski (1980) und Lewicki (2009).

Unter Phraseologismen versteht Fleischer (1997: 72) solche sprachlichen Wortverbindungen, die Idiomatizität, Lexikalisierung, Reproduzierbarkeit und Stabilität aufweisen. "Ihr besonderer Charakter als feste Wortverbindungen ergibt sich vor allem aus ihrer (semantischen) Idiomatizität und ihrer (semantisch-syntaktischen) Stabilität. Damit zusammen hängt ihre Speicherung (Lexikalisierung) als lexikalische Einheit, die bei der Textgestaltung reproduziert wird" (ebd. 1983: 307). Burger (2007: 11, 14-15) definiert Phraseologismen als "feste Wortverbindungen, die obligatorisch aus mehr als einem Wort bestehen (Polylexikalität), nur in bestimmten Kombinationen von Komponenten (eventuell mit Varianten) bekannt und gebräuchlich sind (Festigkeit) und deren lexikalische Bestandteile eine durch die syntaktischen und semantischen Regularitäten der Verknüpfung nicht voll erklärbare Einheit bilden". Grochowski (1982: 23-27) definiert Phraseologismen als aus mindestens zwei Wörtern bestehende Konstruktionen, die gesellschaftlich festgelegt werden und die übertragene Bedeutungen tragen, die anders als Einzelbedeutungen von Komponenten der jeweiligen Phraseologismen sind. Wotjak (1992: 3) ist der Auffassung, dass Phraseologismen "als relativ stabile Verbindungen von Wörtern bzw. Wortgruppen interpretiert werden, deren wendungsinterne Bedeutung sich von der wendungsexternen ihrer Konstituenten in freier Wortverbindung dif-

\footnotetext{
${ }^{5}$ An der Phraseologie erkennen wir die Zugehörigkeit oder vorsätzlichen Identifizierungshandlungen von Personen, wenn es um ihre sozialen Ansichten, politischen Standpunkte oder religiösen Überzeugungen geht. In der Phraseologie [...] sieht man die Dauerhaftigkeit der sprachlichen Übertragung der Gedanken, in den stabilisierten, manchmal ganz erstarrten Wortverbindungen entdecken wir gebrauchsfertige Erklärungen sowie "Halbtexte". - Übersetzung ins Deutsche hier und im ganzen Beitrag - Mariusz Frąckowiak.

${ }^{6}$ Phraseologismen begünstigen die Festigung der Meinungen bezüglich des Weltbildes, der Gesellschaft und des Brauchtums betreffenden Realien der vergangenen Epochen, und auch die Festigung der menschlichen Überzeugungen.
}

ISSN 1615-3014 
ferenziert. Sie werden durch vollständige oder partielle Idiomatizität, Lexikalisierung sowie Reproduzierbarkeit gekennzeichnet".

Für die Zwecke der vorliegenden Untersuchung wird von der Konzeption der Phraseologie im weiteren Sinne ausgegangen, die von denjenigen festen Wortverbindungen vertreten wird, die zwei folgende Eigenschaften aufweisen:

1. Polylexikalität - der Phraseologismus besteht aus mehr als einem Wort.

2. Festigkeit - wir kennen eine feste Wortverbindung in genau dieser Kombination von Wörtern, und sie ist in der Sprachgemeinschaft - ähnlich wie ein Wort - gebräuchlich (vgl. Burger 2007: 14).

"Unter Sprichwörtern werden im Volksmund umlaufende, in sich geschlossene Sprüche von lehrhafter Tendenz und gehobener Form verstanden" (Seiler 2011: 2). "Sprichwörter sind allgemein bekannte, festgeprägte Sätze, die eine Lebensregel oder Weisheit in prägnanter, kurzer Form ausdrücken" (Röhrich/Mieder 1977: 3). Krzyżanowski (1980: 47) definiert sie folgendermaßen: "Przysłowie [...] jest jednostką samodzielną i samowystarczalną, obywającą się bez kontekstu, należy do tych niewielu układów językowych, które są najprostszymi, jednozdaniowymi utworami literackimi"7 . Nach Lewicki (2009: 15-16) funktionieren sie "als Minimaltexte, Zitate und Texte in Texten. Ein Sprichwort hat einen fertigen Inhalt, der von der Situation oder vom Kontext unabhängig ist. In einer Situation oder in einem Kontext wird er nur aktualisiert".

\section{Zeit und Geld als Träger der sprachlichen Universalien in der deutschen und polnischen Phraseologie und Parömiologie - Analyse des Materials}

Die Zeit wird in der deutschen und polnischen Kultur als etwas Abstraktes interpretiert und wird in beiden Sprachgemeinschaften vorzüglich als "Vorübergehen, Ablauf, Nacheinander sowie Aufeinanderfolge von Stunden, Tagen und Jahren" verstanden (vgl. Duden 2007: 1964; Langenscheidt 2003: 1204). Der Duden (www.duden.de/rechtschreibung/Zeit) gibt fünf folgende Bedeutungen der Zeit an:

(1) Ablauf, Aufeinanderfolge der Zeiteinheiten (z. B. Augenblicke, Stunden, Tage, Jahren usw.)

z. B.: im Laufe der Zeit; Zeit vergeht

(2) Zeitpunkt

a. (ugs.) Zeitpunkt; eng begrenzter Zeitraum, Augenblick (z. B.: zur Zeit; es ist Zeit...)

b. Uhrzeit (z. B.: die Zeit ansagen; jmdn. nach der Zeit fragen)

c. Einheitszeit, Normalzeit (im Zusammenhang mit der Zeitzone; z. B.: in Saudi-Arabien gilt Moskauer Zeit)

\footnotetext{
${ }^{7}$ Sprichwort [...] ist eine selbstständige, "autarke", vom Kontext unabhängige Einheit, die zu den wenigen Sprachsystemen gehört, die einfachste, aus einem Satz bestehende literarische Werke sind.
} 


\section{(3) Zeitraum}

a. Zeitraum; Zeitabschnitt, Zeitspanne (z. B.: in absehbarer Zeit; eine schöne Zeit verbringen...)

b. verfügbarer Teil des Nacheinanders, der Abfolge von Augenblicken, Stunden, Tagen, Jahren usw. (z. B.: Spare in der Zeit, so hast du in der Not; die Zeit totschlagen; seine Zeit vergeuden)

c. für eine Leistung benötigter Zeitraum (z. B. im Sportbereich: die Zeit stoppen/nehmen)

d. Dauer eines Spiels (z. B. im Sportbereich: einen Vorsprung über die Zeit bringen)

\section{Zeitraum, Zeitabschnitt des Lebens, der Geschichte usw. (einschließlich der herr- schenden Verhältnisse)}

z. B.: die Zeit Goethes; in Zeiten der Not; [ach] du liebe Zeit!

\section{Zeitform, Tempus (z. B. in der Sprachwissenschaft)}

Tempus/Zeitform des Verbs

Das Geld wird als "vom Staat aus Metall geprägtes oder auf Papier gedrucktes Zahlungsmittel" (Duden 2007: 663) definiert. Dazu gehören Münzen und Banknoten (vgl. Langenscheidt 2003: 407). Derzeit erfreuen sich auch bargeldlose Zahlungsmittel wachsender Beliebtheit. In diesem Falle handelt es sich um Schecks und Kreditkarten (ugs. auch als Plastikgeld bezeichnet) (vgl. Rostek 2003: 16-19). Das Lexem Geld bedeutet zusätzlich sowohl "größere (von einer bestimmten Stelle stammende, für einen bestimmten Zweck vorgesehene) Summe" als auch "Geldkurs" im Börsenwesen (www.duden.de/rechtschreibung/Geld).

Zeit und Geld werden in der Wissenschaft zu den übereinzelsprachspezifischen Komponenten gerechnet, die einen universellen Charakter haben. Dabei kann man von der These ausgehen, dass in unterschiedlichen Sprachen gemeinsame Bestandteile vorhanden sind, die in vielen Kulturgemeinschaften ähnlich oder gleich wahrgenommen werden (vgl. Szczęk 2010: 177). In der Forschungsliteratur, wie beispielsweise in "Phraseologische Universalien", Phraseologie als Objekt der Universalienlinguistik und "Zum Verhältnis des Universellen und Einzelsprachenspezifischen in der Idiomatik (kognitivsemantische Aspekte)" von Dobrovol'skij (1983, 1988, 1998), "Uniwersalne pojęcia ludzkie i ich konfiguracje w różnych kulturach" von Wierzbicka (1991), "Idiommodelle aus psycholinguistischer Sicht als Voraussetzung für das Erschließen des Gemeinsamen und des Besonderen in den einzelnen Sprachen" von Mitschri (1998) sowie Auf der Suche nach der phraseologischen Motiviertheit im Deutschen (am lexikographischen Material) von Szczęk (2010), fungieren solche Elemente als "sprachliche Universalien, die aus den angeblich universellen menschlichen Begriffen resultieren" (ebd.: 176-177).

Zeit sowie Geld gehören zu außersprachlich bedingten phraseologischen Universalien, die sich mehr oder minder, direkter oder weniger direkt auf den Menschen beziehen. Dobrovol'skij (1988: 22) differenziert vier Arten der sprachlichen Universalien: grammatische, phonologische, semantische und symbolische, die eine Grundlage der Internationalismen bilden können (vgl. Szczęk 2010: 178). 
In der Sprachwissenschaft werden Internationalismen als Wörter bzw. Wortgruppen verstanden, die in gleicher Bedeutung und identischer oder ähnlicher Form in verschiedenen Kultursprachen vorkommen (vgl. Duden 2007: 891). Ihr Vorhandensein im Wortschatz vieler Sprachen ergibt sich "v. a. aus der Ähnlichkeit der Lebenserfahrungen, der Denkweise und schließlich den Kontakten zwischen den Völkern" (Szczęk 2010: 174).

\subsection{Analyse der Phraseologismen und Sprichwörter mit der Komponente Zeit}

Die erste Gruppe bilden feste Wortverbindungen, die Vergänglichkeit des Lebens verbalisieren:

1. im Laufe der Zeit, mit der Zeit - z biegem czasu (vgl. www.pons.de) (totale Äquivalenz): 'langsam, nach und nach, allmählich' (vgl. Langenscheidt 2003: 1205),

2. in jüngster Zeit - w ostatnim czasie (vgl. www.pons.de) (totale Äquivalenz): 'während der letzten Wochen oder Tage' (vgl. Langenscheidt 2003: 1205),

3. zu meiner Zeit - za moich czasów (vgl. www.pons.de) (totale Äquivalenz): 'als ich jung war' (vgl. Langenscheidt 2003: 1205),

4. Das waren noch Zeiten! - To byty czasy! (vgl. Wiktorowicz/Frączek 2010: 1149) (totale Äquivalenz): 'damals war es viel besser als heute' (vgl. Duden 2008: 900),

5. seit / vor undenklichen / ewigen Zeiten) - od niepamiętnych czasów (vgl. www.pons.eu) (totale Äquivalenz): 'seit / vor sehr langer Zeit' (vgl. Duden 2008: 901),

6. Die Zeit vergeht wie im Fluge - Czas mija jak z bicza trzasną (vgl. Wiktorowicz/Frączek 2010: 1149) (totale Äquivalenz): 'die Zeit vergeht sehr schnell' (vgl. Langenscheidt 2003: 361).

Die zweite umfangreiche Gruppe bilden Phraseologismen, in denen konkrete Handlungen, Tätigkeiten, Verhaltensweisen bzw. Vorgänge ausgedrückt werden:

1. mit der Zeit gehen - iść z duchem czasu (vgl. Wiktorowicz/Frączek 2010: 1149) (totale Äquivalenz): 'sich so verhalten (in der Kleidung, Sprache usw.), wie es modern ist' (vgl. Langenscheidt 2003: 1205),

2. jemandem Zeit lassen - zostawić komuś czas / dać komuś czas (vgl. Wiktorowicz/Frączek 2010: 1149) (totale Äquivalenz): 'jemandem die Möglichkeit geben, etwas in Ruhe zu tun' (vgl. Langenscheidt 2003: 1205),

3. jemandem / sich (mit etwas) die Zeit vertreiben - umilać komuś / sobie czas (czymś) (vgl. www.pons.de) (totale Äquivalenz): 'jemanden / sich mit etwas (Angenehmem) beschäftigen' (vgl. Langenscheidt 2003: 1205),

4. die Zeit totschlagen - zabijać czas (vgl. Wiktorowicz/Frączek 2010: 1149) (totale Äquivalenz): 'versuchen, sich irgendwie zu beschäftigen (z. B. wenn man irgendwo warten muss o. ä.)' (vgl. Langenscheidt 2003: 1205),

5. sich (für jemanden / etwas) Zeit nehmen / sich die Zeit nehmen - znaleźć czas (na kogoś / coś) (vgl. www.pons.de) (totale Äquivalenz): 'sich einen Freiraum schaffen, um etwas zu tun, das man tun will oder muss' (vgl. Langenscheidt 2003: 1205), 
6. keine Zeit (mit etwas / jemandem) verlieren dürfen - nie móc tracić czasu (na coś / kogoś) (vgl. Wiktorowicz/Frączek 2010: 1149) (totale Äquivalenz): 'etwas sehr schnell tun müssen' (vgl. Langenscheidt 2003: 1205),

7. Zeit gewinnen / herausschlagen / schinden - zyskiwać na czasie (vgl. www.pons.de) (totale / partielle Äquivalenz): 'es erreichen, dass sich das Eintreten bestimmter, besonders ungünstiger Umstände verzögert und man Zeit für entsprechendes Handeln hat' (vgl. Duden 2007: 1965),

8. jemandem die Zeit stehlen / rauben (vgl. Duden 2008: 900) - kraść / zabierać komuś czas (vgl. www.pons.de) (totale Äquivalenz): 'jemanden unnötig aufhalten, jemanden mit lästigen oder überflüssigen Fragen quälen' (vgl. Duden 2007: 900),

9. auf Zeit spielen - grać na czas (vgl. Wiktorowicz/Frączek 2010: 1149) (totale Äquivalenz): 'das Spieltempo absichtlich verzögern, um das Ergebnis zu halten' (vgl. Duden 2008: 901),

10. die Zeichen der Zeit erkennen - rozpoznawać znaki czasu (vgl. www.pons.de) (totale Äquivalenz): 'die Situation, Lage (im Hinblick auf kommende Entwicklungen) richtig einschätzen' (vgl. Duden 2008: 898),

11. Zeit für jemanden / etwas opfern - ofiarować komuś / czemuś czas (vgl. www.pons.de) (totale Äquivalenz): 'sich um jemanden kümmern, sich eingehend mit etwas beschäftigen' (vgl. Röhrich 2012: 1764).

In manchen festen Wortverbindungen und Sprichwörtern wird die Zeit personifiziert:

1. Die Zeit drängt - Czas nagli (vgl. Wiktorowicz/Frączek 2010: 1149) (totale Äquivalenz): 'etwas muss schnell getan werden, weil es sonst dafür zu spät ist' (vgl. Langenscheidt 2003: 1205),

2. Jemandem läuft die Zeit davon - Czas komuś ucieka (vgl. Wiktorowicz/Frączek 2010: 1149) (totale Äquivalenz): 'die Zeit vergeht so schnell, dass jemand (wahrscheinlich) nicht erledigen kann, was er sich vorgenommen hat' (vgl. Langenscheidt 2003: 1205),

3. Die Zeit arbeitet für jemanden - Czas pracuje na czyjąś korzyść (www.pons.de) (totale Äquivalenz): 'die Gegebenheiten ändern sich nach und nach zu jmds. Gunsten (ohne sein Zutun)' (vgl. Duden 2008: 899),

4. (Die) Zeit heilt (alle) Wunden - Czas leczy (goi, zabliźnia) (wszystkie) rany / Czas to najlepszy lekarz (vgl. Wiktorowicz/Frączek 2010: 1149) (totale Äquivalenz): 'auch Schmerz und Trauer kann man irgendwann überwinden' (vgl. Langenscheidt 2003: 1205),

5. Kommt Zeit, kommt Rat - Przyjdzie czas, przyjdzie rada / Przyjdzie czas, znajdzie sie rada (vgl. Wiktorowicz/Frączek 2010: 1149) (totale Äquivalenz): 'es ergibt sich vielleicht eine Lösung für ein Problem, wenn man nur geduldig abwartet, was passiert' (vgl. Langenscheidt 2003: 1205).

In zwei Phraseologismen und einem Sprichwort wird die Zeit materialisiert:

1. der Zahn der Zeit - ząb czasu (vgl. Wiktorowicz/Frączek 2010: 1145) (totale Äquivalenz): 'die im Laufe der Zeit auftretenden Zerstörungen' vgl. Duden 2008: 893), 
2. (noch) Zeit haben - mieć (jeszcze) czas (vgl. www.pons.de) (totale Äquivalenz): 'nicht eilig sein' (vgl. Duden 2008: 900),

3. Zeit ist Geld - Czas to pieniadz (vgl. Wiktorowicz/Frączek 2010: 1149) (totale Äquivalenz): 'verwendet, um auszudrücken, dass die Zeit wertvoll ist und (sinnvoll) genutzt werden sollte' (vgl. Langenscheidt 2003: 1205).

Die nächste Gruppe bilden zwei feste Wortverbindungen, die eine (bestimmte) Dauer bedeuten:

1. eine Zeit lang - przez pewien czas (vgl. www.pons.de) (totale Äquivalenz): 'für eine relativ kurze Zeit' (vgl. Langenscheidt 2003: 1205),

2. auf Zeit - na czas (vgl. Wiktorowicz/Frączek 2010: 1149) (totale Äquivalenz): '(nur) für eine bestimmte Dauer, befristet' (vgl. Langenscheidt 2003: 1205),

3. für alle Zeiten / für Zeit und Ewigkeit - za wszystkie czasy, po wsze czasy, na wieczne czasy (vgl. Wiktorowicz/Frączek 2010: 1149) (totale Äquivalenz): 'für immer' (vgl. Langenscheidt 2003: 1205).

Es lassen sich zwei Phraseologismen nachweisen, in denen Wechselhaftigkeit bzw. Unbeständigkeit thematisiert werden:

1. Andere Zeiten, andere Sitten - Czasy się zmienia / Inne czasy, inne obyczaje (vgl. Wiktorowicz/Frączek 2010: 1149) (totale Äquivalenz): 'Bräuche, Wertvorstellungen u. a. ändern sich im Verlauf der Zeit' (vgl. Duden 2008: 899),

2. Die Zeiten ändern sich - Czasy się zmieniaja (totale Äquivalenz): 'die (besonders gesellschaftlichen) Normen, Verhältnisse und Bräuche ändern sich' (vgl. Langenscheidt 2003: 1205).

Mittels der festen Wortverbindungen kann man die Unregelmäßigkeit bzw. Seltenheit zum Ausdruck bringen:

1. von Zeit zu Zeit - od czasu do czasu czasu (vgl. www.pons.de) (totale Äquivalenz): 'gelegentlich' (vgl. Duden 2008: 901),

2. Alle heiligen Zeiten (einmal)! - Raz na jakiś czas! (vgl. Wiktorowicz/Frączek 2010: 1149) (totale Äquivalenz): '(höchst) selten, in großen zeitlichen Abständen' (vgl. Duden 2008: 899).

Manche Zeit-Phraseologismen beziehen sich auf einen genauen bzw. konkreten Zeitpunkt:

1. zu gegebener (zur rechten / richtigen) Zeit - we właściwym / odpowiednim czasie (vgl. www.pons.de) (totale Äquivalenz): 'rechtzeitig, zu dem richtigen oder passenden Zeitpunkt' (vgl. Langenscheidt 2003: 1205),

2. Es wird (höchste / allerhöchste) Zeit / Es ist an der Zeit / Es ist (höchste / allerhöchste / hohe) Zeit - Zbliża się czas / Już czas / Najwyższy czas (vgl. Wiktorowicz/Frączek 2010: 1149) (totale Äquivalenz): 'jetzt ist es nötig (etwas zu tun)' (vgl. Langenscheidt 2003: 1205), 
3. Es ist an der Zeit (für etwas, etwas zu tun) - Już czas / Najwyższy czas (coś zrobić) (vgl. Wiktorowicz/Frączek 2010: 1149) (totale Äquivalenz): 'der Zeitpunkt (für etwas, etwas zu tun) ist gekommen' (vgl. Duden 2008: 901),

4. Alles zu seiner Zeit! - Wszystko w swoim czasie! (vgl. Wiktorowicz/Frączek 2010: 1149) (totale Äquivalenz): 'man soll nichts zu schnell tun' (vgl. Langenscheidt 2003: 1205),

5. (nur) eine Frage der Zeit sein - być (tylko) kwestia czasu (vgl. Wiktorowicz/Frączek 2010: 355) (totale Äquivalenz): 'innerhalb einer bestimmten Zeit zwangsläufig eintreten' (vgl. Duden 2008: 238).

\subsection{Analyse der Phraseologismen und Sprichwörter mit der Komponente Geld}

Die erste umfassende Gruppe bilden diejenigen Phraseologismen, die implizit menschliche Charakterzüge behandeln:

a. Geiz:

auf seinem Geld sitzen / auf dem Geld sitzen wie der Teufel auf der armen Seelesiedzieć na pieniadzach (vgl. www.pons.de) (totale / partielle Äquivalenz): 'jemand ist geizig' (vgl. Langenscheidt 2003: 407).

b. Sparsamkeit:

Geld im Sparstrumpf / unter der Matratze verstecken - odkładać pieniadze do skarpety (vgl. Wiktorowicz/Frączek 2008: 509) (totale / partielle Äquivalenz): 'sparen, sparsam sein'.

c. Verschwendung:

1. mit Geld um sich werfen / schmeißen - szastać pieniędzmi (vgl. www.pons.de) (partielle Äquivalenz): '(sehr) verschwenderisch sein' (vgl. Röhrich 2012: 530),

2. das Geld mit vollen Händen ausgeben (vgl. Duden 2008: 271) - szastać pieniędzmi (partielle Äquivalenz): '(sehr) verschwenderisch sein',

3. sein / das Geld (mit beiden / vollen Händen) zum Fenster hinauswerfen / rausschmeißen / aus dem Fenster werfen / zum Schornstein hinausjagen / sein / das Geld (mit beiden / vollen Händen) auf die Straße werfen (vgl. Duden 2008: 271) - wyrzucać pieniadze w błoto vgl. Wiktorowicz/Frączek 2010: 387) (totale / partielle Äquivalenz): 'sein Geld verschwenden, sein Geld leichtfertig ausgeben, sehr verschwenderisch sein' (vgl. Duden 2008: 271),

4. jemandem rinnt das Geld durch die Finger - pieniądze się kogoś nie trzymaja / pieniądze przeciekaja komuś przez palce (vgl. Wiktorowicz/Frączek 2010: 387) (totale Äquivalenz): 'verschwenderisch sein' (vgl. Duden 2008: 270),

5. das / sein Geld unter die Leute bringen - szastać pieniędzmi pieniędzmi (vgl. Wiktorowicz/Frączek 2010: 387) (partielle Äquivalenz): 'das Geld (rasch) ausgeben, kauflustig sein, das Verdiente rasch wieder ausgeben' (vgl. Duden 2008: 270). 
Die meisten festen Wortverbindungen drücken konkrete Handlungen, Tätigkeiten, Verhaltensweisen bzw. Vorgänge aus:

1. etwas für teures Geld kaufen - kupować coś za ciężkie / duże / grube pieniądze (vgl. www.pons.de) (totale Äquivalenz): 'viel Geld für etwas bezahlen' (vgl. Langenscheidt 2003: 407),

2. dickes Geld gewinnen - wygrać grube pieniądze pieniądze (vgl. Wiktorowicz/Frączek 2010: 387) (totale Äquivalenz): 'sehr viel Geld gewinnen',

3. jemandem (das) Geld aus der Tasche ziehen - wyciagać od kogoś pieniadze / wytudzać pieniadze od kogoś / naciagać kogoś na pieniądze (vgl. Wiktorowicz/Frączek 2010: 387) (partielle Äquivalenz): 'jemanden dazu bringen, Geld auszugeben / jemandem eine überhöhte Rechnung ausstellen' (vgl. Duden 2007: 663),

4. Geld scheffeln - zgarniać mase pieniędzy / zarabiać (robić) na czymś pieniadze (partielle Äquivalenz): 'sehr viel Geld verdienen',

5. mit etwas (das große) Geld machen - zrobić na czymś pieniadze pieniadze (vgl. www.pons.de) (totale Äquivalenz): '(sehr viel) Geld verdienen' (vgl. Duden 2008: 270),

6. die Jagd nach Geld - gonitwa za pieniędzmi pieniędzmi (vgl. Wiktorowicz/Frączek 2010: 387) (totale Äquivalenz): 'Streben nach Geld'.

Zur nächsten Gruppe gehören diejenigen Phraseologismen, die den gesellschaftlichen Status (Vermögen bzw. Reichtum) bezeichnen:

\section{a. reich werden:}

zu Geld kommen - dojść do pieniędzy (vgl. Wiktorowicz/Frączek 2010: 387) (totale Äquivalenz): 'reich werden' (vgl. Duden 2007: 663).

b. reich sein:

1. Geld wie Dreck / Heu / Mist haben (vgl. Duden 2008: 270) - mieć pieniędzy jak lodu (vgl. Wiktorowicz/Frączek 2010: 387) (partielle Äquivalenz): 'reich sein',

2. im / in Geld schwimmen - leżeć / siedzieć na pieniądzach (vgl. www.pons.de) (partielle Äquivalenz): 'reich sein' (vgl. Langenscheidt 2003: 407).

In manchen Phraseologismen und Sprichwörtern wird das Geld personifiziert:

1. Geld allein macht nicht glücklich (aber es beruhigt) - Pieniądze szczęścia nie daja (vgl. Wiktorowicz/Frączek 2010: 387): 'zum Glücklichsein braucht man mehr als nur Geld' (vgl. Duden 2008: 270),

2. Geld regiert die Welt - Pieniadz rzadzi światem (vgl. Wiktorowicz/Frączek 2010: 387) (totale Äquivalenz): 'wer über Geld verfügt, hat auch Macht und Einfluss' (vgl. Duden 2008: 270),

3. Geld stinkt nicht - Pieniądze nie śmierdza śmierdza (vgl. Wiktorowicz/Frączek 2010: 387) (totale Äquivalenz): 'verwendet, um auszudrücken, dass man nicht erkennen kann, auf welche Weise jemand sein Geld verdient hat' (vgl. Langenscheidt 2003: 407). 
Manche festen Wortverbindungen definieren die Art und Weise, wie man das Geld verdienen bzw. gewinnen kann:

1. leichtes Geld verdienen - zarobić łatwe pieniadze (vgl. Wiktorowicz/Frączek 2010: 387) (totale Äquivalenz): 'auf leichte Art und Weise Geld verdienen',

2. das Geld liegt auf der Straße - pieniadze leża na ulicy (vgl. www.pons.de) (totale Äquivalenz): 'man kann leicht Geld verdienen' (vgl. Duden 2008: 270),

3. heißes Geld - lewe pieniadze (vgl. Wiktorowicz/Frączek 2010: 387) (partielle Äquivalenz): 'unlauteres Geld',

4. die Jagd nach Geld - gonitwa za pieniędzmi (vgl. Wiktorowicz/Frączek 2010: 387) (totale Äquivalenz): 'Streben nach Geld'.

Die nächste Gruppe bilden Phraseologismen, die Geldmenge charakterisieren:

1. etwas für teures Geld kaufen - kupować coś za ciężkie / duże / grube pieniądze (vgl. www.pons.de) (totale Äquivalenz): 'viel Geld für etwas bezahlen' (vgl. Langenscheidt 2003: 407),

2. dickes Geld gewinnen - wygrać grube pieniadze (vgl. Wiktorowicz/Frączek 2010: 387) (totale Äquivalenz): 'sehr viel Geld gewinnen',

3. Geld scheffeln - zgarniać masę pieniędzy / zarabiać (robić) na czymś pieniądze (vgl. www.pons.de) (partielle Äquivalenz): 'sehr viel Geld verdienen',

4. mit etwas (das große) Geld machen - zrobić na czymś pieniadze pieniadze (vgl. www.pons.de) (totale Äquivalenz): '(sehr viel) Geld verdienen' (vgl. Duden 2008: 270),

5. eine Stange / ein Haufen Geld - grube / duże pieniądze / kupa pieniędzy (totale Äquivalenz): 'sehr viel Geld' (vgl. Duden 2008: 726).

Eine große Gruppe der festen Wortverbindungen bilden diejenigen Phraseologismen, die sich auf den Wert des Geldes beziehen:

1. etwas für teures Geld kaufen - kupować coś za ciężkie / duże / grube pieniadze (vgl. www.pons.de) (totale Äquivalenz): 'viel Geld für etwas bezahlen' (vgl. Langenscheidt 2003: 407),

2. dickes Geld gewinnen - wygrać grube pieniadze (totale Äquivalenz): 'sehr viel Geld gewinnen',

3. mit etwas (das große) Geld machen - zrobić na czymś pieniadze pieniadze (vgl. www.pons.de (totale Äquivalenz): '(sehr viel) Geld verdienen' (vgl. Duden 2008: 270),

4. Geld allein macht nicht glücklich (aber es beruhigt) (vgl. Wiktorowicz/Frączek 2010: 387) (totale Äquivalenz) - Pieniadze szczęścia nie dają: 'zum Glücklichsein braucht man mehr als nur Geld' (vgl. Duden 2008: 270),

5. Geld regiert die Welt - Pieniądz rządzi światem światem (vgl. Wiktorowicz/Frączek 2010: 387) (totale Äquivalenz): 'wer über Geld verfügt, hat auch Macht und Einfluss' (vgl. Duden 2008: 270), 
6. nicht für Geld und gute Worte - za żadne skarby (vgl. Wiktorowicz/Frączek 2010: 387) (partielle Äquivalenz): 'sich nicht zu etwas überreden lassen' (vgl. Langenscheidt 2003: 407), 'um keinen Preis' (vgl. Duden 2008:271).

\section{Schlussfolgerungen}

Die sprachliche Untersuchung hat aufgezeigt, dass in ein- und zweisprachigen Wörterbüchern zahlreiche Phraseologismen und Sprichwörter an Zeit und Geld fixiert bzw. unter diesen Stichworten registriert sind. Im Beitrag sind 33 Zeit-Phraseologismen und 21 GeldPhraseologismen sowie 4 Zeit-Sprichwörter und 3 Geld-Sprichwörter einer konfrontativen und quantitativen Analyse unterzogen worden. Es lässt sich Folgendes feststellen:

1. Die meisten Phraseologismen und alle untersuchten Sprichwörter weisen in den beiden Sprachen vollständige Äquivalenz auf: Jemandem läuft die Zeit davon - Czas komuś ucieka oder Geld stinkt nicht-Pieniądze nie śmierdzą.

2. Im Korpus kann man nur die wenigen festen Wortverbindungen finden, die partielle Äquivalenz in den beiden Sprachen aufweisen: Zeit herausschlagen - zyskiwać na czasie oder mit Geld um sich werfen / schmeißen - szastać pieniędzmi. Zu dieser Gruppe gehören unter anderem diejenigen Phraseologismen, die entweder im Deutschen oder im Polnischen umschrieben werden müssen: Das Geld mit vollen Händen ausgeben - szastać pieniędzmi oder Geld scheffeln - zgarniać masę pieniędzy / zarabiać (robić) na czymś pieniądze.

3. Im untersuchten Material überwiegen v. a. verbale Phraseologismen und Sprichwörter, die mit unterschiedlichen Verben auftreten. Die verbalen Komponenten konstituieren die Bedeutungen der festen Wortverbindungen bzw. Sprichwörter mit: Die Zeit drängt - Czas nagli oder Jemandem rinnt das Geld durch die Finger - Pieniadze się kogoś nie trzymaja / Pieniadze przeciekaja komuś przez palce. Die Bedeutungen können auch aus adjektivischen Bestandteilen resultieren: Seit / vor undenklichen / ewigen Zeiten - od niepamiętnych czasów oder dickes Geld gewinnen - wygrać grube pieniadze.

4. Die im Titel genannten Lexeme werden in den beiden Sprachgemeinschaften auf gleiche oder ähnliche Art und Weise konzeptualisiert, z. B.:

a. Die Zeit- und Geld-Phraseologismen drücken dieselben Handlungen, Tätigkeiten, Verhaltensweisen bzw. Vorgänge in den beiden Sprachen aus: Mit der Zeit gehen - iść z duchem czasu oder mit etwas (das große) Geld machen - zrobić na czymś pieniadze.

b. Sowohl die Zeit als auch das Geld werden in den beiden Kulturen (v. a. in Sprichwörtern) sehr gerne personifiziert: Die Zeit arbeitet für jemanden - Czas pracuje na czyjąś korzyść, (Die) Zeit heilt (alle) Wunden - Czas leczy (goi, zabliźnia) (wszystkie) rany / Czas to najlepszy lekarz, Kommt Zeit, kommt Rat - Przyjdzie czas, przyjdzie rada / Przyjdzie czas, znajdzie się rada, Geld allein macht nicht glücklich (aber es beruhigt) - Pieniądze szczesścia nie daja, Geld regiert die Welt-Pieniądz rzadzi światem. 
c. Die Zeit wird in manchen festen Wortverbindungen und einem Sprichwort als etwas Materielles bzw. Konkretes dargelegt: (noch) Zeit haben - mieć (jeszcze) czas und Zeit ist Geld - Czas to pieniadz.

Die Untersuchung zahlreicher Belege lässt erkennen, dass das sprachliche Weltbild ${ }^{8}$ der Zeit und des Geldes in den beiden Kulturen in den meisten Fällen identisch ist. Es wird analog sowohl in der deutschen als auch in der polnischen Phraseologie und Parömiologie verbalisiert. Darüber hinaus können beide Titellexeme als sprachinterne Universalien gelten, die für das lexikalische und phraseologische Subsystem kennzeichnend sind und in der Phraseologie und Parömiologie der beiden Sprachen viele lexikalisch-semantische Gemeinsamkeiten und einige Ähnlichkeiten aufweisen. Zeit und Geld werden im Deutschen und Polnischen identisch bzw. ähnlich abgebildet. Beide Begriffe tragen deswegen einen universellen Charakter.

5. Die meisten analysierten festen Wortverbindungen und alle untersuchten Sprichwörter können als Interphraseologismen bzw. Träger der phraseologischen Universalien verstanden werden, weil sie im Deutschen und Polnischen mittels des ähnlichen bzw. gleichen Wortbestandes zum Ausdruck gebracht werden und dieselben metaphorischen Bedeutungen tragen. Dabei haben sie vollständige Äquivalente in den beiden Sprachen: Der Zahn der Zeit - ząb czasu und Kommt Zeit, kommt Rat - Przyjdzie czas, przyjdzie rada / Przyjdzie czas, znajdzie się rada oder im / in Geld schwimmen leżeć / siedzieć na pieniądzach und Geld stinkt nicht-Pieniądze nie śmierdzą.

6. Die meisten Zeit- und Geld-Phraseologismen sowie alle Sprichwörter tragen in den beiden Sprachen einen identischen, figurativen Sinn: Jemandem die Zeit stehlen / rauben - kraść / zabierać komuś czas und auf seinem Geld sitzen / auf dem Geld sitzen wie der Teufel auf der armen Seele - siedzieć na pieniadzach oder Zeit ist Geld-Czas to pieniadz und Geld allein macht nicht glücklich (aber es beruhigt) - Pieniadze szczęścia nie dają. Die übertragenen Bedeutungen erlangen die Phraseologismen sowie Sprichwörter erst dank zusätzlichen Komponenten, die mit dem Geld und der Zeit unterschiedliche Einheiten bilden. Beide Titellexeme gelten dabei als Kerne aller untersuchten Wendungen, derer Inhalt sich auf Hauptbedeutungen des Geldes und der Zeit bezieht.

7. In allen untersuchten Geld-Phraseologismen wird das Geld in den beiden Sprachen in seinen zwei Grundbedeutungen gebraucht, d. h. als vom Staat aus Metall geprägtes oder auf Papier gedrucktes Zahlungsmittel: Jemandem (das) Geld aus der Tasche ziehen - wyciagać od kogoś pieniadze / wytudzać pieniadze od kogoś / naciagać kogoś na pieniadze bzw. als etwas Wertvolles und Wesentliches: Geld regiert die Welt - Pieniądz rządzi światem.

8. Anhand des Korpus kann man feststellen, dass die Zeit in den beiden Kulturen sehr oft als Vergänglichkeit verstanden wird: Die Zeit vergeht wie im Fluge - Czas mija jak z

\footnotetext{
${ }^{8}$ Das sprachliche Weltbild wird verstanden als "eine Ansammlung von Regelmäßigkeiten, die in den kategorialen grammatischen Beziehungen (die Flexion, die Wortbildung und die Syntax) und semantischen lexikalischen Strukturen enthalten sind, und welche die für eine Sprache eigentümliche Wahrnehmungsweise der Welt und allgemeines Verstehen der Weltgestalt, auch aller in der Welt vorhandenen hierarchischen Beziehungen und bestimmter Werte, die in einer Sprachgemeinschaft anerkannt werden, darstellt" (Tokarski 1993: 358, zit. in Szczęk 2010: 20).
} 
bicza trzasnat, im Laufe der Zeit, mit der Zeit - z biegem czasu, zu meiner Zeit - za moich czasów und in jüngster Zeit - w ostatnim czasie.

\section{Literatur}

Bralczyk, Jerzy (2004): Język na sprzedaż. Gdańsk: Gdańskie Wydawnictwo Psychologiczne. Burger, Harald (2007): Phraseologie. Eine Einführung am Beispiel des Deutschen. Berlin: Schmidt.

Dobrovol'skij, Dmitrij (1983): "Phraseologische Universalien". In Bahner, Werner/Schildt, Joachim/Viehweger, Dieter (Hrsg.): Proceedings of the XIVth International Congress of Linguistics. Bd. 3. Berlin, Akademie Verlag: 2355-2358.

Dobrovol'skij, Dmitrij (1988): Phraseologie als Objekt der Universalienlinguistik. Leipzig: Enzyklopädie.

Dobrovol'skij, Dmitrij (1998): "Zum Verhältnis des Universellen und Einzelsprachenspezifischen in der Idiomatik (kognitivsemantische Aspekte)". In: Eismann, Wolfgang (Hrsg.): Europhras '95. Europäische Phraseologie im Vergleich. Bochum, Brockmeyer: 151-163.

Duden (2007): Deutsches Universalwörterbuch. Mannheim usw.: Dudenverlag.

Duden (2008): Redewendungen. Wörterbuch der deutschen Idiomatik. Bd. 11. Mannheim usw.: Dudenverlag.

Duden Rechtschreibung. www.duden.de/rechtschreibung/Geld [16.11.2014] und www.duden.de/rechtschreibung/Zeit [16.11.2014].

Fleischer, Wolfgang (1983): "Phraseologie". In: Fleischer, Wolfgang (Hrsg.): Kleine Enzyklopädie Deutsche Sprache. Leipzig, Lang: 307-321.

Fleischer, Wolfgang (1997): Phraseologie der deutschen Gegenwartssprache. Tübingen: Niemeyer.

Grochowski, Maciej (1982): Zarys leksykologii i leksykografii, Zagadnienia synchroniczne. Toruń: Wydawnictwa UMK.

Krzyżanowski, Julian (1980): Szkice folklorystyczne, t. 3. Kraków: Wydawnictwo Literackie. Langenscheidt (2003): Großwörterbuch Deutsch als Fremdsprache. Berlin: Langenscheidt.

Lewicki, Andrzej Maria (2009): Studia z polskiej frazeologii. Łask: Oficyna Wydawnicza LEKSEM.

Mitschri, Elena (1998): "Idiommodelle aus psycholinguistischer Sicht als Voraussetzung für das Erschließen des Gemeinsamen und des Besonderen in den einzelnen Sprachen". In: Eismann, Wolfgang (Hrsg.): Europhras '95. Europäische Phraseologie im Vergleich. Bochum, Brockmeyer: 523-534.

Pajdzińska, Anna (2006): Studia frazeologiczne. Łask: Oficyna Wydawnicza LEKSEM.

Pons Online Wörterbuch. www.pons.de [16.11.2014].

Rostek, EwaMaria (2003): Deutsch. Lesen und Verstehen. Teksty o tematyce spolecznoekonomicznej. Poznań: WAGROS.

Röhrich, Lutz/Mieder, Wolfgang (1977): Sprichwort. Stuttgart: Metzlersche Verlagsbuchhandlung.

Seiler, Friedrich (2011): Deutsche Sprichwörterkunde. München: Beck.

Siewert, Katarzyna (2012): "(Deutsche) Phraseologie als rechtskulturelles Erbe". In: Bartoszewicz, Iwona/Szczęk, Joanna/Tworek, Artur (Hrsg.): Im Anfang war das Wort I. Bd. 8. 
Wrocław/Dresden: Oficyna Wydawnicza ATUT - Wrocławskie Wydawnictwo Oświatowe/Neisse: 287-294.

Szczęk, Joanna (2010): Auf der Suche nach der phraseologischen Motiviertheit im Deutschen (am lexikographischen Material. Dresden/Wrocław: Neisse/Oficyna Wydawnicza ATUT Wrocławskie Wydawnictwo Oświatowe.

Szober, Stanisław (1937): "Echa Biblii we frazeologii polskiej". In: Szober, Stanisław: Na straży języka. Warszawa, Nasza Księgarnia: 93-96.

Wierzbicka, Anna (1991): "Uniwersalne pojęcia ludzkie i ich konfiguracje w różnych kulturach". In: Etnolingiwstyka 4. Lublin, Wydawnictwo UMCS: 7-40.

Wiktorowicz, Józef/Frączek, Agnieszka (2008): Wielki słownik polsko-niemiecki. Großwörterbuch Polnisch-Deutsch. Warszawa: Wydawnictwo Naukowe PWN.

Wiktorowicz, Józef/Frączek, Agnieszka (2010): Wielki słownik niemiecko-polski. Großwörterbuch Deutsch-Polnisch. Warszawa: Wydawnictwo Naukowe PWN.

Wotjak, Barbara (1992): Verbale Phraseolexeme in System und Text. Tübingen: Niemeyer. 